\title{
DESIGN AND STRENGTH CALCULATIONS OF THE TRIPOD SUPPORT STRUCTURE FOR OFFSHORE POWER PLANT
}

\author{
C. Dymarski, Prof. \\ P. Dymarski, Ph. D. \\ J. Żywicki, Ms. C. \\ Gdańsk University of Technology, Poland
}

\begin{abstract}
The support structure being the object of the analysis presented in the article is Tripod. According to the adopted assumptions, it is a foundation gravitationally set in the water region of $60 \mathrm{~m}$ in depth, not fixed to the seabed, which can be used for installing a 7MW wind turbine. Due to the lack of substantial information on designing and strength calculations of such types of structures in the world literature, authors have made an attempt to solve this problem within the framework of the abovementioned project. In the performed calculations all basic loads acting on the structure were taken into account, including: the self mass of the structure, the masses of the ballast, the tower and the turbine, as well as hydrostatic forces, and aero- and hydrodynamic forces acting on the entire object in extreme operating conditions.
\end{abstract}

Keywords: offshore wind turbine, support structure, Morison equation, FEM

\section{INTRODUCTION}

The here presented work has been done within the framework of the research project AQUILO entitled "Development of methods for the selection of the type of support structure for offshore wind turbine in Polish sea areas".

The purpose of the task in which this research was implemented was to design a support structure in a given area of the Polish economic zone on the Baltic Sea. Within this project four types of structures were analysed: a gravity base, a tripod with pile foundation, a gravity tripod, and a deep water monopile.

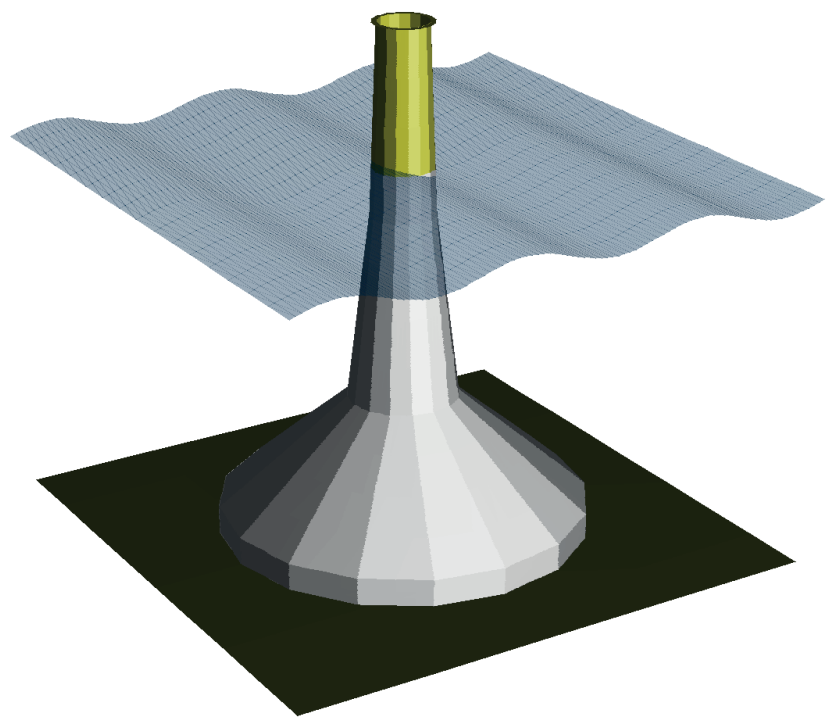

Fig. 1a. Three types of support structures analyzed within the framework of the project - Gravity base

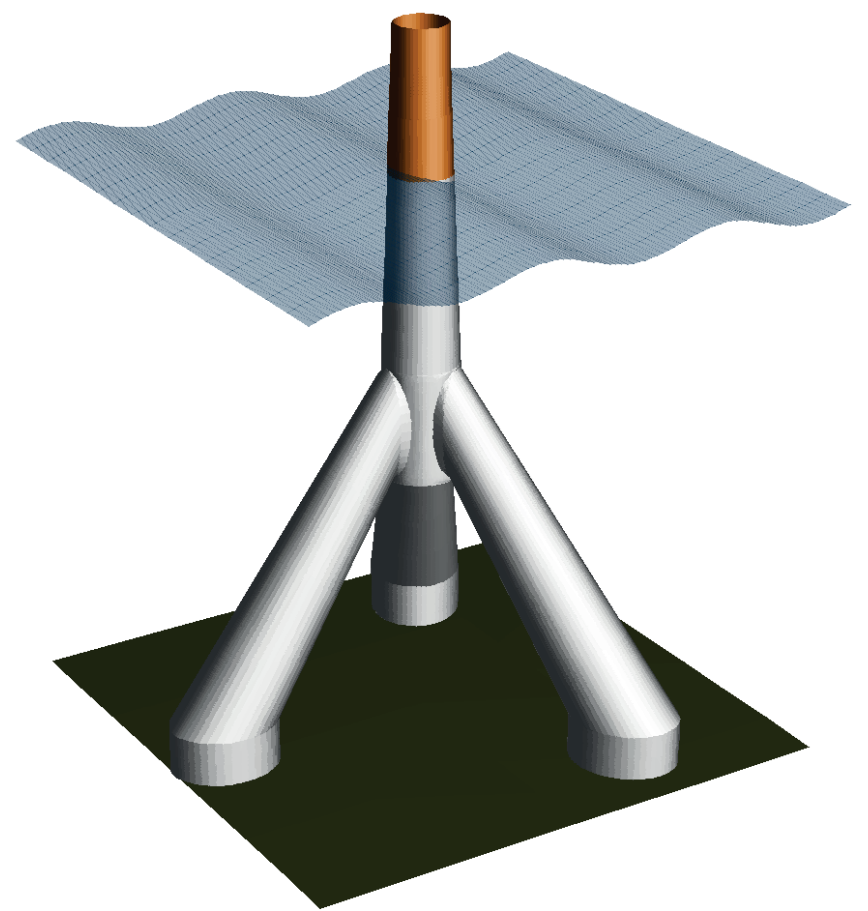

Fig. 1b. Three types of support structures analyzed within the framework of the project - Gravity tripod

The support structure being the object of the analysis presented in the article is Tripod. According to the adopted assumptions, it is a gravitationally set foundation, not fixed to the seabed, which can be used for installing a $7 \mathrm{MW}$ wind turbine in the water region of $60 \mathrm{~m}$ in depth. Due to the lack 
of substantial information on designing and calculations of such types of structures in the world literature, authors have made an attempt to solve this problem within the framework of the abovementioned project. The object was assumed to be loaded with: the self weight, wind pressure, outer hydrostatic pressure (seawater), inner hydrostatic pressure (liquid ballast), and the hydrodynamic action of the environment.

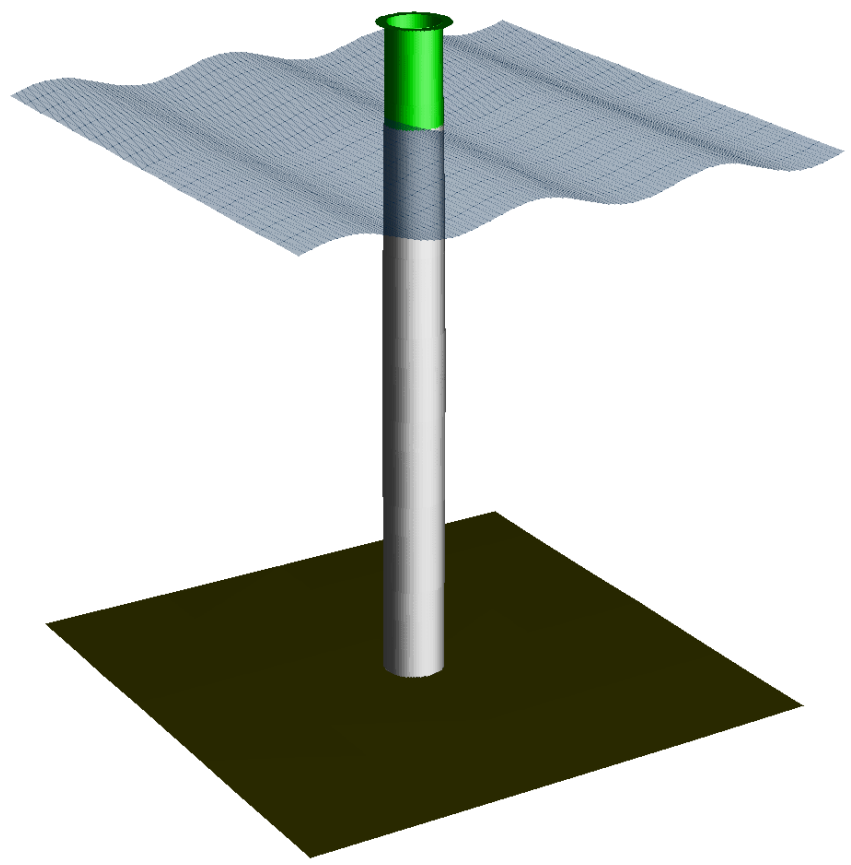

Fig. 1c. Three types of support structures analyzed within the framework of the project - Monopile

\section{CALCULATION OF HYDRODYNAMIC FORCES}

\section{MORISON EQUATION}

The total hydromechanical force which acts on a motionless body placed in the unsteady, unidirectional flow of fluid can by expressed by [1]:

$$
F=\frac{1}{2} C_{D} \rho A_{p}|U| U+\rho V_{b}\left(1+C_{a}^{\prime}\right)\left(\frac{\partial U}{\partial t}+U \frac{\partial U}{\partial x}\right)
$$

where $A_{p}$ is the projected area of the body on the plane normal to the direction of the flow $\mathrm{V}_{\mathrm{b}}$, is the volume of the body, $\mathrm{C}_{\mathrm{D}}$ and $\mathrm{C}^{\prime}$ are the drag and added mass coefficients, $\mathrm{U}$ is the velocity, and $\rho$ is the water density.

Coefficients $\mathrm{C}_{\mathrm{D}}$ and $\mathrm{C}_{\mathrm{a}}$ depend on time, geometry of the body, Reynolds number Rn, and parameters describing the history of the flow (for example the amplitude and time interval of velocity variation). In practice, they are plotted as functions of the Keulegan-Carpenter number $\mathrm{K}_{\mathrm{C}}$ and the so called $\beta=$ $=\mathrm{Rn} / \mathrm{K}_{\mathrm{C}}$ coefficient proposed by Sarpkaya [1].

The Morison equation is a simplified version of equation (1), obtained after assuming that the term $\mathrm{dU} / \mathrm{dt}$ in the equation can be approximated by $9 \mathrm{u} / \vartheta_{\mathrm{t}}$, hence:

$$
F=\frac{1}{2} \rho C_{D} A_{p}|U| U+\rho C_{M} V_{b} \frac{\partial U}{\partial t}
$$

where:

$\mathrm{C}_{\mathrm{M}}=1+\mathrm{C}_{\mathrm{a}}$, and $\mathrm{C}_{\mathrm{a}}$ is the time averaged value of $\mathrm{C}_{\mathrm{a}}$.

The above equation is used for calculations of cylindrical shapes. When the motion of fluid particles caused by waves is to be analysed, this equation can be applied when the cylinder diameter is not greater than about $20 \%$ of the wave length $\lambda$.

Coefficients $C_{M}$ and $C_{D}$ can be obtained from model tests. Sarpkaya $[1,2]$ carried out a systematic study, based on which the characteristics of coefficients $C_{M}$ and $C_{D}$ were derived for a cylindrical shape as functions of $\mathrm{K}_{\mathrm{C}}, \beta$, and relative roughness $\mathrm{k}_{\mathrm{r}} / \mathrm{D}$. Values of these coefficients for other geometries are also available in the literature [1,3], Fig 2, 3.

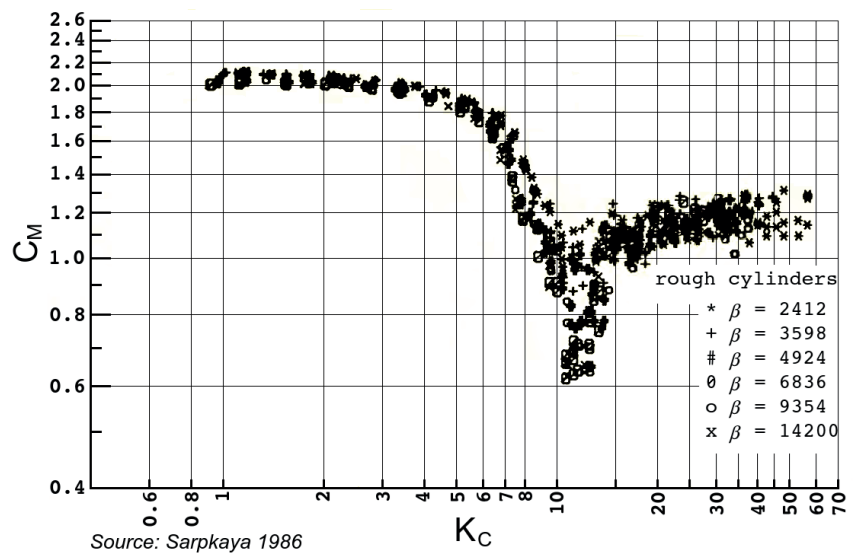

Fig. 2. Comparison of inertia coefficient CM for six rough cylinders, $k_{r} / D=50$. Source: Sarpkaya [2].

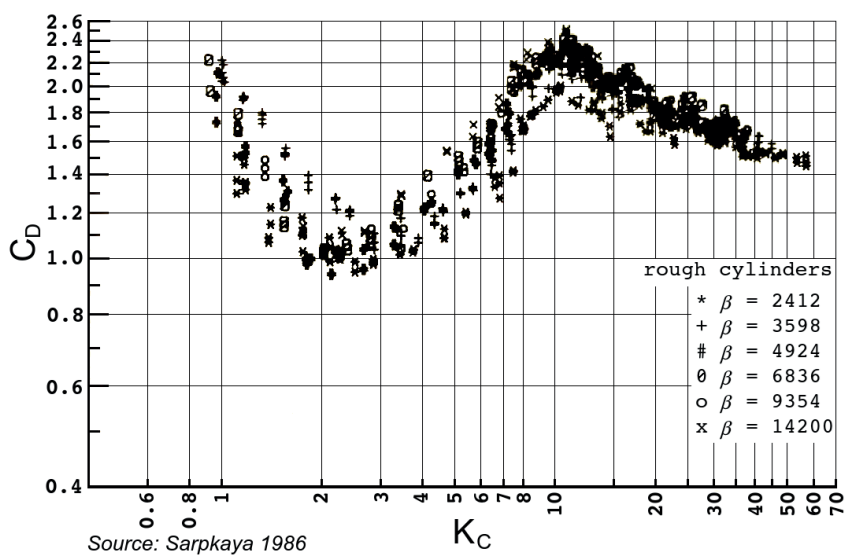

Fig. 3. Comparison of drag coefficient CD for six rough cylinders, $k_{r} / D=50$. Source: Sarpkaya [2].

GENERAL FORM OF THE MORISON EQUATION USED FOR CALCULATING THE IMPACT OF THE UNSTEADY AND NON-UNIFORM FLOW ON THE SUPPORT STRUCTURE.

In the previously presented equations an assumption is made that the velocity vector is perpendicular to the axis of the 
cylinder and the velocity field is uniform. In the general case, for example, when dealing with the velocity field appearing in the wave motion, the velocity field is not uniform, and the direction of flow (and acceleration) is subject to changes. The geometry of the structure varies as well. Therefore the force acting on the section of a structure element needs to be determined using the general formula:

$$
\Delta F=\left(\frac{1}{2} \rho C_{D} D\left|U_{n}\right| U_{n}+\frac{1}{4} \pi D^{2} \rho C_{M} \frac{\partial}{\partial t} U_{n}\right) \Delta s
$$

The velocity vector normal to the longitudinal axis of the element of structure is given by:

$\mathrm{Un}=\mathrm{U}-(\mathrm{U} \cdot \mathrm{es}) \mathrm{es}$, where: $\mathrm{U}$ is the velocity vector, es is the unit vector tangent to the axis of the structure, $\Delta s$ is the length of the section of the element in which the hydrodynamic force is calculated, $\mathrm{D}$ is the diameter of the section (or the longest diagonal if the section is a polygon). It is assumed that $\mathrm{CM}$ and $\mathrm{CD}$ coefficients are functions of $\mathrm{KC}, \beta$, and of the geometry of the analysed section (and adjacent sections).

The value of the force acting on the element can be therefore determined as the integral:

$$
F=\int_{0}^{s}\left(\frac{1}{2} \rho C_{d} D\left|U_{n}\right| U_{n}+\frac{1}{4} \pi D^{2} \rho C_{m} \frac{d}{d t} U_{n}\right) d s
$$

\section{DETERMINING THE VELOCITY FIELD DUE TO WAVES AND CURRENTS}

So far, we have assumed that the velocity field is a known quantity. However, determining the velocity field is not a simple task. The Maritime Institute in Gdansk analysed the hydrometeorological data for a particular sea area and performed statistical calculations, based on which a set of basic parameters of the waves and sea current was obtained [5].

In the project, the assumed lifetime of the structure was 30 years, with an optional extension for further 20 years, therefore, the analysis took into account parameters of a violent storm, the one which happens once in 50 years. Velocities of the sea currents in the Baltic are relatively low. To calculate the desired parameters, it was assumed in the project that the speed of the sea current at the surface is $U_{\text {curr }}(0)=0.45 \mathrm{~m} / \mathrm{s}$, which is the velocity that appears once in 50 years in the water region of interest.

Figure 4 presents the wave spectrum distribution for a specific set of data, whereas Figure 5 presents the function of the sea current velocity.

The resulting velocity field is a sum of the sea current velocity and the velocity field due to waves:

$$
U=U_{\text {curr }}+U_{\text {wave }}
$$

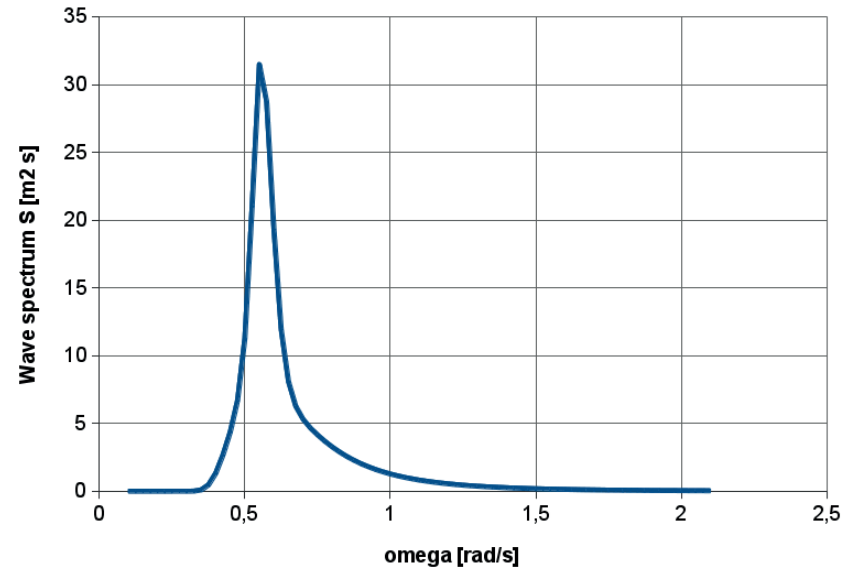

Fig. 4. Wave spectrum JONSWAP for the 50-year storm: $T_{p}=11.3 \mathrm{~s}$; $H_{\mathrm{s}}=9.01 \mathrm{~m} ; \gamma=4.14$

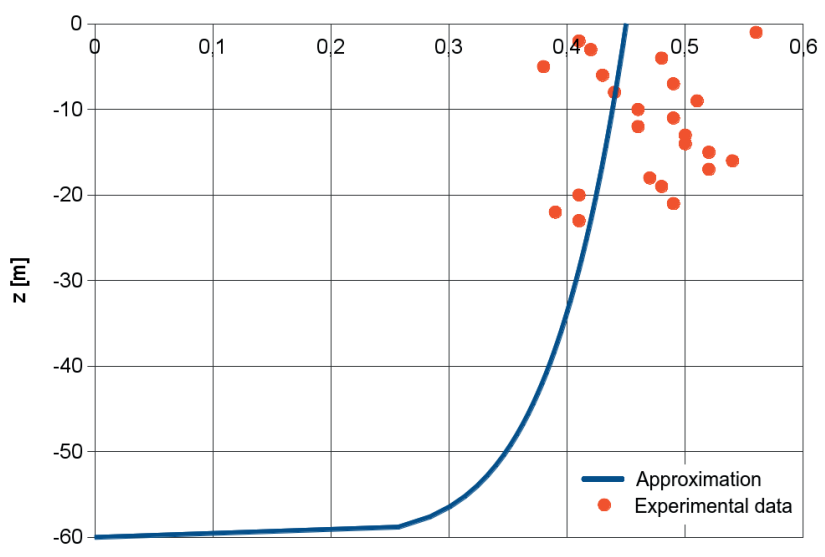

Ucurr (z) $[\mathrm{m} / \mathrm{s}]$

Fig. 5. Approximation of the current velocity profile for the 50-year storm [5]

\section{CALCULATION OF HYDRODYNAMIC RESPONSE}

The wave spectrum with the parameters described in the above Section corresponds to the storm duration of 3 hours. For this spectrum three wave functions were randomly chosen, each of one hour duration. Additionally, the calculations took into account the presence of the sea current.

The results of calculations for the wave at which the maximum load of the structure was observed are shown below. Figure 6 shows the bending moment relative to the bottom of the structure $(\mathrm{z}=-60 \mathrm{~m})$ as a function of time. It was assumed that the maximum load is such that the bending moment of the structure reaches its maximum. For the here presented results the maximum stress occurs at time $\mathrm{t}=3450.5 \mathrm{~s}$.

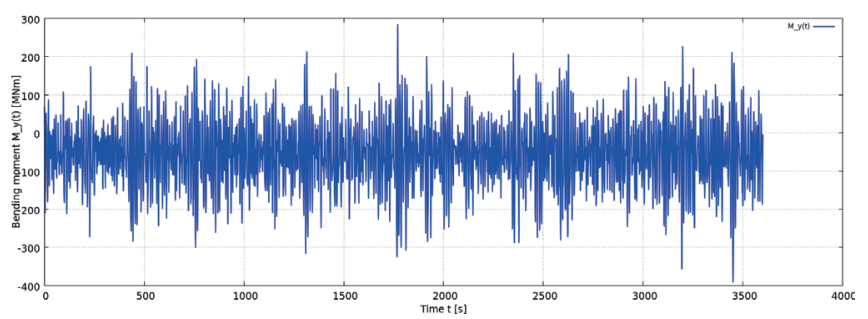

Fig. 6. The total bending moment $M y$ (at $z=-60 \mathrm{~m})$ induced on the structure by the wave and current 


\section{DESCRIPTION OF THE INITIAL STRUCTURE}

The foundation was designed as a thin-wall structure, the shape of which resembles a tripod. Similar marine structures are already in operation, but they differ by foundation methods. For the time being, they have been used in more shallow waters and their legs were fixed to the seabed using piles. The here presented structure is intended to be used in conditions characteristic for the Baltic Sea, in its southern region at an approximate depth of $60 \mathrm{~m}$, and is assumed to be founded on the seabed only with the aid of gravitational forces. That is why the shape of the lower part of the structure is designed in such a way that, after proper ballasting of the inside, the foundation is ready to carry maximum loads taking place during its operation, with no shift with respect to the seabed. The support structure comprises a column divided into two basic parts. The upper part has the shape of a cone, with a ring on one end for mounting the wind turbine tower, while the lower part has the shape of a cylinder of $8 \mathrm{~m}$ in diameter. Three legs, evenly distributed by 120 degrees and inclined at 60 degrees to the vertical, are welded directly to the cylinder. The lower part of each of these legs is shaped as an elliptical cylinder with vertical walls, frequently referred to as the "hoof" or foot. The hoofs were connected together using horizontal pipes of about $1 \mathrm{~m}$ in diameter. The footbase area is a circle of about $30 \mathrm{~m}$ in radius. The overall dimensions and thickness of the sheeting for preliminary calculations are given in Fig. 7.
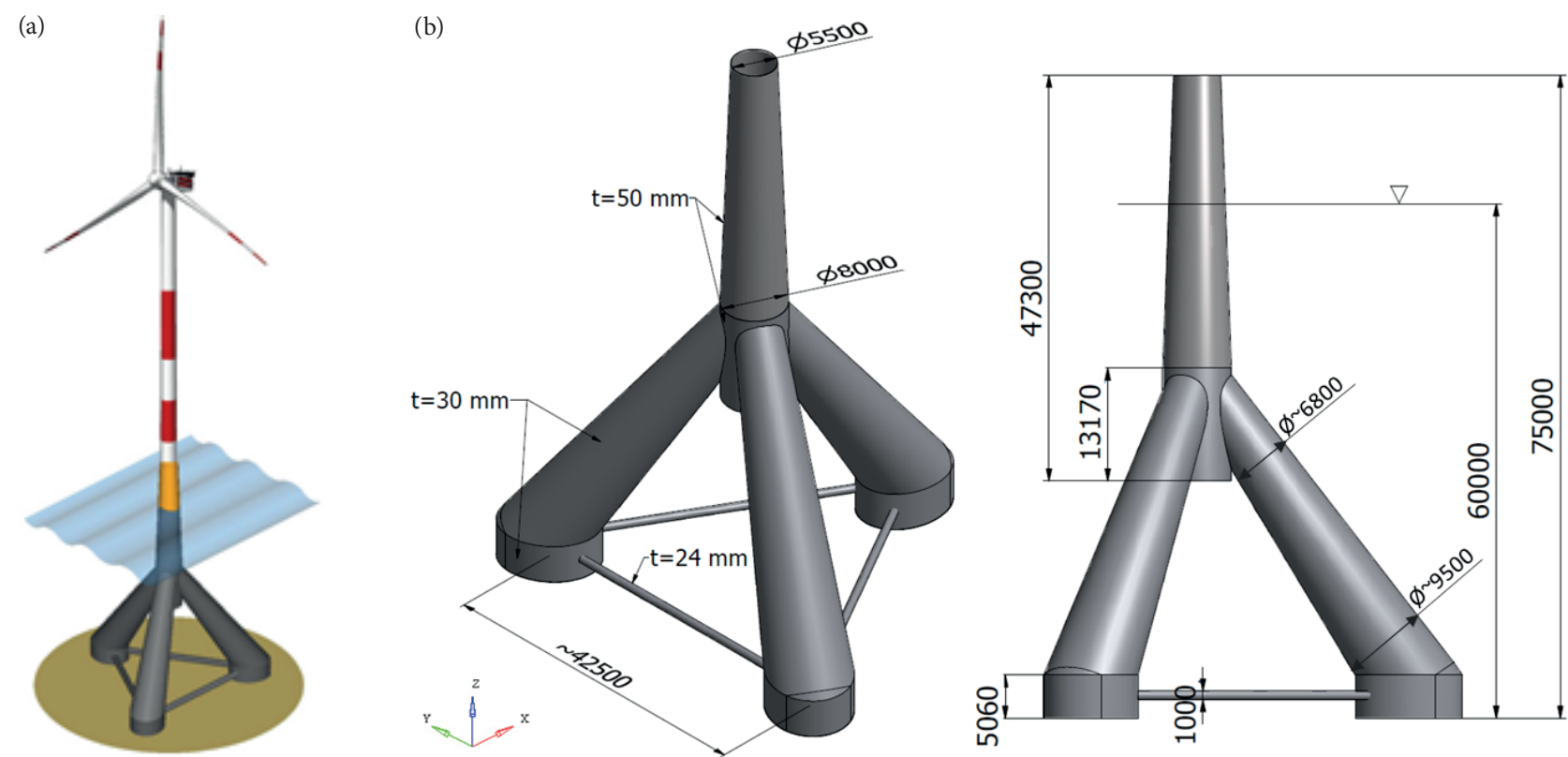

Fig. 7. Basic geometric parameters of the support structure. [6]

\section{LOADS AND OPERATING CONDITIONS OF THE SUPPORT STRUCTURE}

The below described loads and conditions of operation of the support structure are the same for each stage of structure geometry modifications described in the article. The presented results of consecutive simulations were obtained for these assumptions. As already mentioned, the structure was assumed to be founded in the Baltic Sea area at the depth of $60 \mathrm{~m}$. The upper flange to which the column will be fixed is situated 15 $\mathrm{m}$ over the water surface. The loads of the structure coming from environmental conditions were generated during a hydromechanical simulation taking into account the conditions corresponding to the most violent storm in recent 50 years on the Baltic Sea. In these calculations, the worst conditions for the structure were assumed which take place when the wind loads, i.e. the thrust and the torque, mostly generated on the turbine, and the hydromechanical forces act along the same Y-direction.

Technical parameters of the turbine which were used for calculating foundation loads are collected in Tablel 1 .
Tab. 1: Technical parameters of the turbine

\begin{tabular}{|l|l|}
\hline Turbine power: & $7 \mathrm{MW}$ \\
\hline Turbine hub height above sea level & $100 \mathrm{~m}$ \\
\hline Thrust & $2,9 \mathrm{MN}$ \\
\hline Turbine diameter & $126 \mathrm{~m}$ \\
\hline Mass of nacelle and rotor & $480 \mathrm{t}$ \\
\hline Mass of column & $458 \mathrm{t}$ \\
\hline
\end{tabular}

Based on the hydromechanical simulation, the distribution of horizontal loads coming from the sea current, waves, and the wind was determined as the function of the height of the object. For calculating purposes, the model was divided into 2-metre long segments, and the averaged horizontal load acting on each segment was calculated. The zero level was assumed at the bottom of the structure, while the water surface corresponded to the height of $60 \mathrm{~m}$. The distribution of continuous load along the height of the structure is shown in Fig. 8. The forces coming from the aerodynamic drag of the tower, the thrust generated by the turbine, and the self weight were reduced to 
the upper flange of the support structure. The following load values were obtained: torque $-260 \mathrm{MNm}$, lateral force $-3,23$ $\mathrm{MN}$, vertical force $-9,2 \mathrm{MN}$.

The hydrostatic pressures of the sea water and the pulp used for ballasting the foundation act in the structure in the following way:

- Sea water acts on the structure along the distance from the wave bottom $(\mathrm{h}=-10 \mathrm{~m}$, below the average sea water level) to the seabed $(\mathrm{h}=-60 \mathrm{~m})$. The density of sea water was assumed as equal to $1026 \mathrm{~kg} / \mathrm{m} 3$ (marked blue in Fig. 9)

- The ballast (pulp) acts on the inner surface of the structure up to the average water surface level. The density of the pulp was assumed as equal to $1700 \mathrm{~kg} / \mathrm{m} 3$. (marked red in Fig. 9)

The assumed model of load aims at simulating the conditions when, in heavy seaway, the wave bottom reaches the depth of $10 \mathrm{~m}$, and the hydrostatic pressure of the ballast inside the structure is not balanced by the pressure coming from the sea water. The distribution of pressures along the structure is shown in Fig. 9.

\section{DISCRETE MODEL}

The lump model of the support structure shown in Fig. 7 was created in the Autodesk Inventor package. Then, the programme HyperMesh was used to obtain midsurfaces, which made the basis for generating a grid with the aid of P-Shell elements: second-order tetragons and triangles taken from the library of the Radios (Optistruct) solver. The elements used in the first iteration calculations are collected in Table 2.

Tab. 2: List of elements

\begin{tabular}{|c|c|c|c|c|c|}
\hline & \multirow{3}{*}{ Nodes } & \multicolumn{2}{|c|}{ 2D elements } & \multirow{2}{*}{$\begin{array}{l}\text { 1D elements } \\
\text { Perfectly rigid }\end{array}$} & \multirow{3}{*}{ Degrees of freedom } \\
\hline & & Square & \begin{tabular}{|l} 
Triangular \\
\end{tabular} & & \\
\hline & & CQUAD8 & CTRIA6 & RIGID & \\
\hline Number & 1998431 & 660412 & 6452 & 384 & 11232222 \\
\hline Average dimension $[\mathrm{mm}]$ & - & 90 & 90 & 2750 & ـ \\
\hline
\end{tabular}

The connection areas between the support structure and the turbine tower were modelled using perfectly rigid elements connected together in the central node, to which loads were applied in the form of the torque and forces coming from the action of the wind on the higher situated tower and turbine, and from their self weight - Fig. 10.

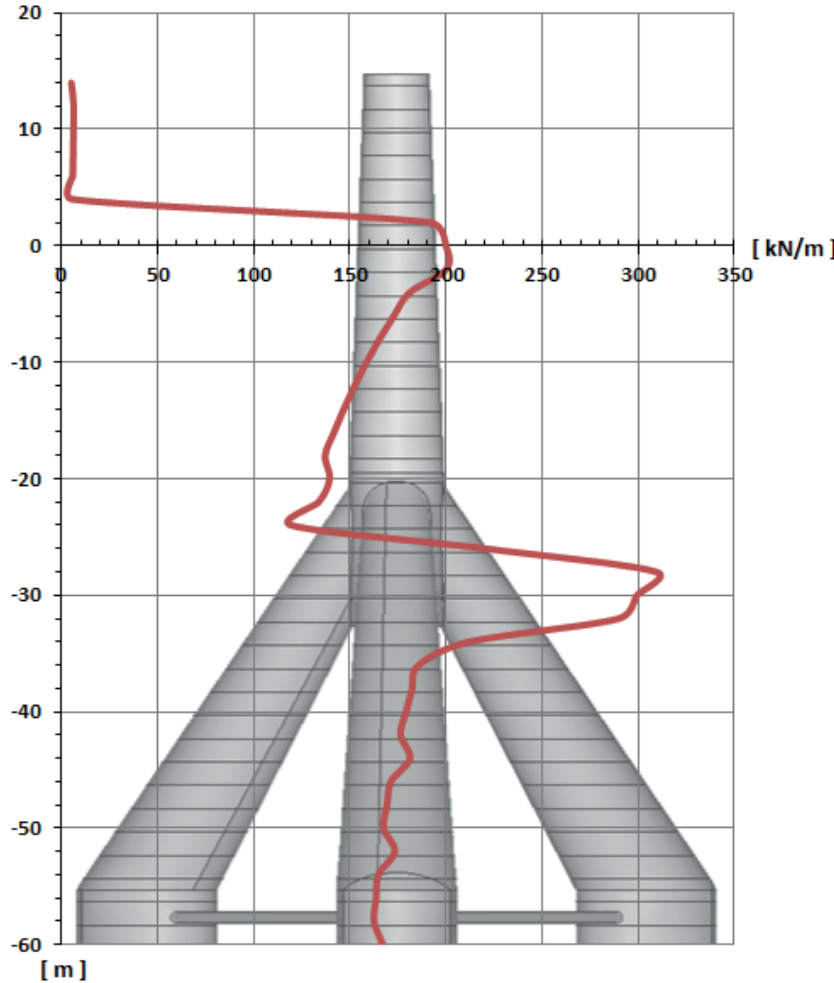

Fig. 8. Continuous load acting at given height.

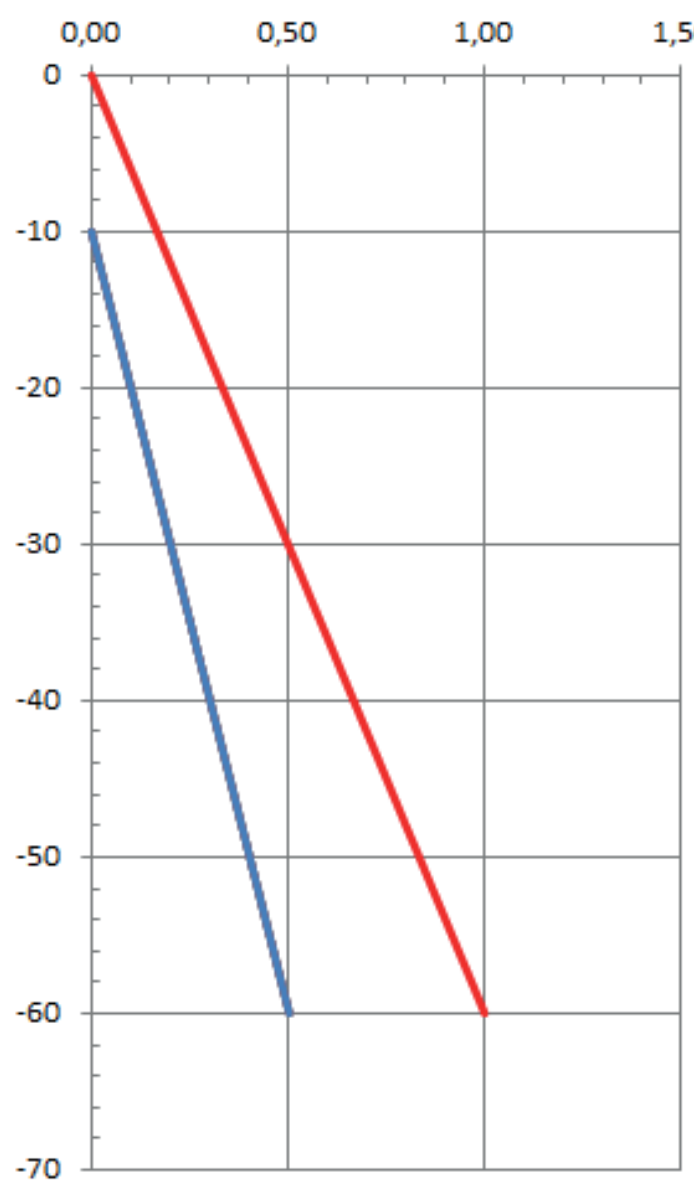

[m]

Fig. 9. Hydrostatic load acting on the structure 


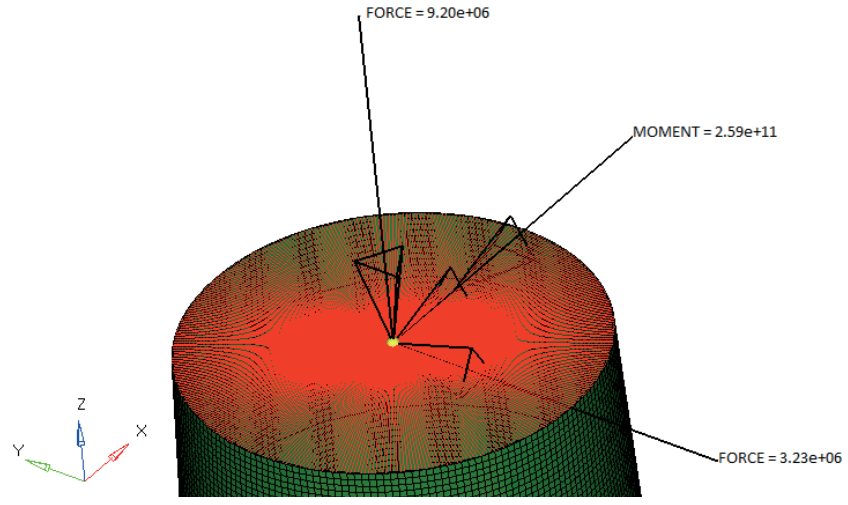

Fig. 10. Central node "flange"

\section{MODEL OF THE MATERIAL}

The assumed linear-elastic model of the material revealed the following properties:

- $\quad$ Young's modulus $\mathrm{E}=210 \mathrm{GPa}$

- $\quad$ Poisson ratio $v=0.3$

- $\quad$ density $\rho=7860 \mathrm{~kg} / \mathrm{m} 3$

\section{LOAD APPLICATION}

According to the above description, the FEM model was loaded at the central point with a negative torque of about $260 \mathrm{MNm}$ along the X-direction and the lateral force of 3.23 $\mathrm{MN}$ acting along the Y-direction.

The loads from the masses of the wind tower column (458 $\mathrm{t}$ ), and the nacelle and rotor (480 t) were applied as the 9.2 MN force to the node on the upper flange.

The gravitational acceleration $a=9.81 \mathrm{~m} / \mathrm{s} 2$ with the negative sense was applied along the Z-direction. According to the assumptions described in the previous Section, the hydrodynamic load of the structure was applied to nodes along the Y-direction. The grid of the model was divided into horizontal segments of $2 \mathrm{~m}$ in height, and then the numbers of nodes composing particular segments were counted. Each of these nodes was loaded with a force which was calculated by dividing the total load of the given segment obtained from CFD simulation by the number of nodes. A decision to make use of the above model was dictated by the fact that hydrodynamic pressures are much smaller than hydrostatic pressures acting on the foundation. Their action generates the bending moment, which is a remarkable load for the structure. The adopted load distribution does not affect much the local strength of the structure, and remarkably facilitates data preparation for calculations. The hydrostatic pressure was applied along the normal direction to the seabed and the sheeting, according to the assumptions shown in Fig. 9.

\section{FEM CALCULATIONS}

The structure strength calculations were performed using the Finite Element Method (FEM) and the HyperWorks v12 package produced by Altair. The programme HyperMesh, which in authors' opinion is an excellent tool for grid preparation and imposing boundary conditions to such a large surface model, was used as preprocessor. Linear calculations were performed using the solver Optistruct, while the results were displayed using the postprocessor HyperView. The simulation was performed on PC equipped with a 4-core, 64-bit processor Intel I7 $2.30 \mathrm{GHz}, 16 \mathrm{~GB}$ of RAM DDR3, and the hard disc SSD $840 \mathrm{PRO}$. The calculations for the structure at final stages of geometry modifications, in which the number of finite surface elements was approximately equal to 1 million, took about 2.5 hours.

\section{STRENGTH CALCULATIONS OF THE INITIAL STRUCTURE}

For the purpose of preliminary analyses, a structure was worked out without inner stiffening elements in order to detect places which would require installation of additional structural elements. A motivation for this decision was to avoid excessive dimensioning of the structure. In the first simulation the model was fixed at the seabed by removing the ability to move in $\mathrm{X}, \mathrm{Y}, \mathrm{Z}$-directions from the nodes composing the bottom of the structure.

Figures 11 and 12 show contour maps presenting the distributions of stresses $[\mathrm{MPa}]$ and deformations $[\mathrm{mm}]$ in the initial structure.
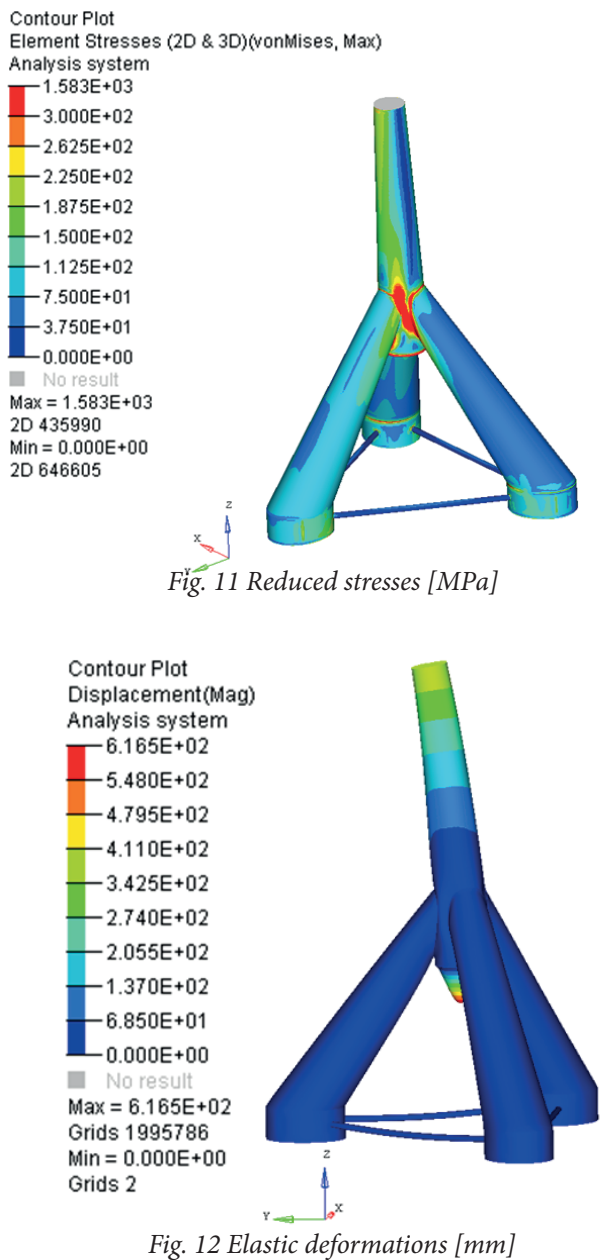
As had been expected, the largest stresses, amounting to near $1600 \mathrm{MPa}$, were observed in the connection areas of the legs with the outer sheeting of the cylindrical part of the column. The maximal load generated displacements along the Y-direction were recorded on the upper flange and amounted to about $400 \mathrm{~mm}$. The displacement along the $\mathrm{Z}$-direction, of about $600 \mathrm{~mm}$, was caused by the action of the ballast pressure on the unstiffened plate of the cylinder bottom. The mass of the structure was $1307 \mathrm{t}$.

Due to very high stresses recorded in the analyses structure, its geometry had to be modified in the regions where maximal stresses were observed.

\section{MODIFICATIONS}

- The obtained results have led to the conclusion that the areas in which the legs are connected with the column should be remarkably reinforced. A decision was made to shift the upper ends of the legs to the inside of the cylinder and link them together on common wedges. During further structure geometry changes, rings and special T-type $(600 \times 30 \times 200 \times 30)$ stiffeners were introduced to the inner surfaces of the legs in the area where they cross the cylindrical part of the column. Stiffeners situated closer to the axis of the structure were linked together, while the height of the remaining stiffeners was reduced, as can be seen in the enlarged section of Fig. 13.

- The plate of $50 \mathrm{~mm}$ in thickness which constituted the cylinder bottom was radially stiffened using trusses of dimensions T1200x30x330x30.

- In order to perform the simulation for most unfavourable conditions assuming the absence of friction forces between the legs, moving along with the accompanying ground, and the seabed, the method of model supporting was changed. The ability to move along X,Y,Z-directions was removed from the nodes composing the base of this leg which was most pressed to the seabed, while the remaining two legs were allowed to move in the X-Y plane. This simplification went in a safe direction, as in fact, part of normal forces carried by horizontal pipes of the structure should be taken over by friction forces acting between the legs and the bottom of the water region.

The results of the simulation performed for the support structure modified in the above way are shown in Fig. 13. The scale was selected in such a way that the red colour indicates stresses exceeding $300 \mathrm{MPa}$.

The introduced geometry changes resulted in the reduction of maximal stresses to about $1100 \mathrm{MPa}$, also the area of occurrence of critical stresses ( $\sigma \mathrm{r}>300 \mathrm{MPa}$ ) became smaller. The displacement of the top of the support structure column also decreased and amounted to $277 \mathrm{~mm}$. The change of boundary conditions at the contact with the basis to enable leg spreading resulted in stretching of the horizontal pipes, which provoked stresses amounting to about $900 \mathrm{MPa}$ in the area of their contact with the hoops. The reason for such high stresses was the absence of stiffeners in the pipe/hoop connection region.

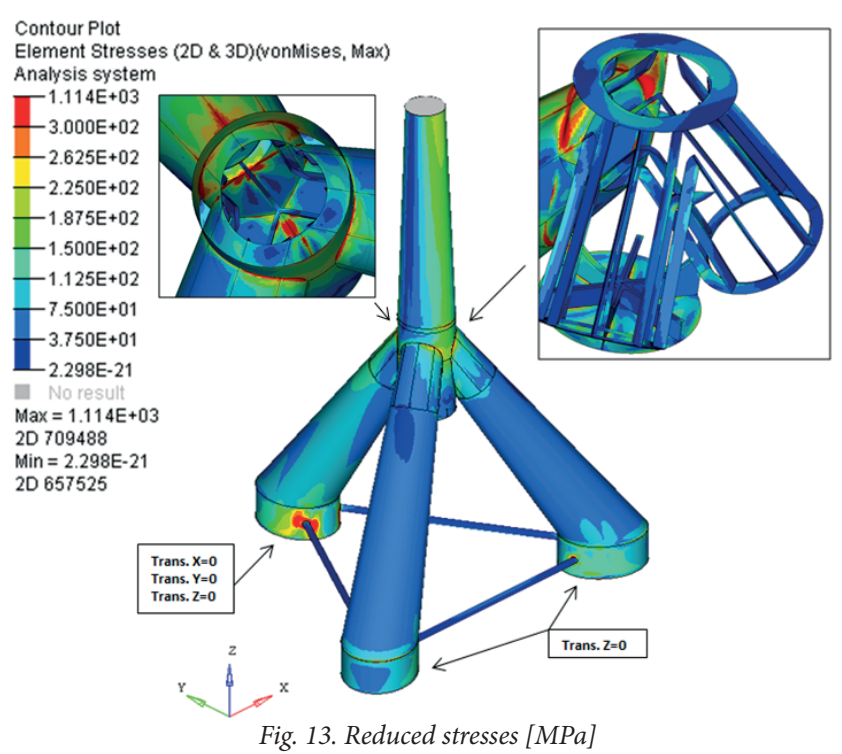

The displacement of the legs in the X-Y plane was equal to about $25 \mathrm{~mm}$. The mass of the analysed structure was $1416 \mathrm{t}$.

An attempt to decrease the stresses in most vulnerable places of the structure has led to its further modification.

- Another ring was installed in the leg/column connection region, on the inner surface of each leg, and the number of inner stiffeners along their perimeter was increased.

- The structure which closes the cylinder bottom was reinforced with extra bulb flats $430 \times 20$, arranged into a shape of concentric hexagons, which, along with radial trusses composed a grate.

- Triangular vertical plates of $30 \mathrm{~mm}$ in thickness were added to reinforce the upper sheeting of the cylindrical part. These plates played a role of gussets improving the stress distribution in the leg/cylinder connection area.

The adopted geometry changes remarkably decreased the stresses and the area of their occurrence, without changing the thickness of the material used for outer sheeting, as shown in Fig. 14

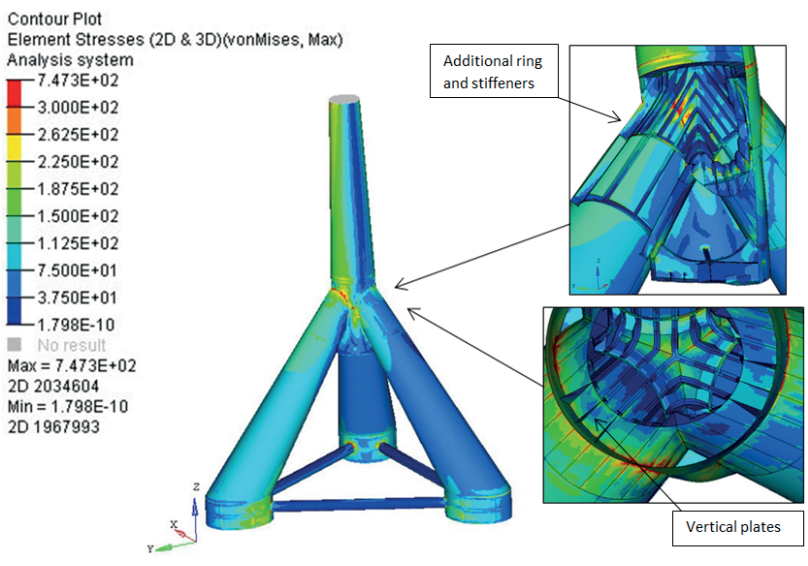

Fig. 14. Reduced stresses [MPa] 
The structure of the lower parts of the legs (hoops) in which high stresses had been observed as a result of the action of forces taken over from the stretched horizontal pipes was modified in the following way :

- $\quad$ Lower parts of the legs were remarkably modified. The sheeting of the bottom which had been earlier unstiffened was reinforced with trusses $(\mathrm{T} 1000 \times 30 \times 300 \times 30)$ and bulb flats $430 \times 20$.

- $\quad$ Two ring stiffeners (T500x30x200x30) were added in the horizontal plane.

- $\quad$ Ends of the horizontal pipes were moved to the insides of the hoops by about $1 \mathrm{~m}$ and additionally linked with the stiffeners.

- The diameter of the pipes was increased from $\mathrm{z} 1 \mathrm{~m}$ to $2 \mathrm{~m}$.

The stress distribution resulting from the above geometry changes introduced to the lower part of the structure is shown in Fig. 15.

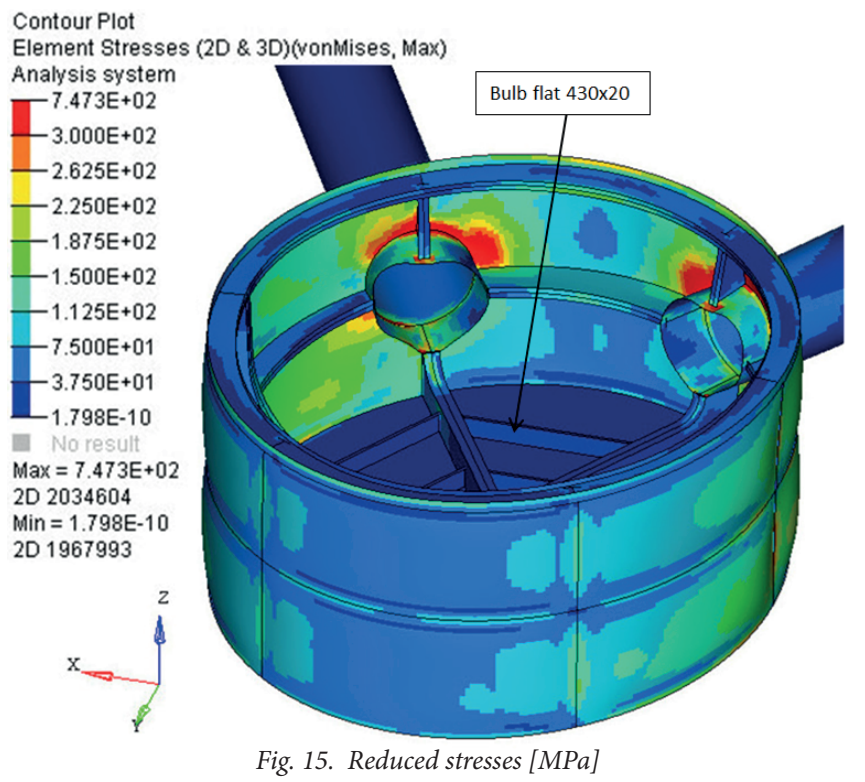

\section{MODEL TAKING INTO ACCOUNT SEABED PLASTICITY}

The next stage of modelling oriented on improving the accuracy of the simulation took into account the plasticity of the seabed. Solving this problem required the knowledge about physical properties of the seabed structure in the water region of interest. It is noteworthy that this information is, generally, available, as one of the initial stages of investments projects of this type is examination of the seabed structure in the area of future foundation of the supporting structures. However at present, due to the lack of access to the results of this examination, the simulation was performed for the seabed stiffness taken from the standard PN-80/B-03040
"Foundations and supporting structures for machines" [7]. The ground stiffness coefficient $\mathrm{C}_{\mathrm{z}}=40 \mathrm{MPa} / \mathrm{m}$ was chosen from Table 1 in the above standard, which corresponds to the "low-stiffness II category ground, silty sands, hydrated".

The plasticity of the ground was modelled using spring type elements. The nodes situated at the bottom of legs were copied and moved apart by the distance of $1 \mathrm{~m}$ along the $\mathrm{Z}$-direction, and the elements of spring type "Celas_1" from the library of the solver Radios, which reveal stiffness at the longitudinal direction, were inserted between them. The stiffness of the individual spring was calculated using the following formula:

$$
K_{i}=\frac{\mathrm{C}_{\mathrm{z}} \cdot A}{\mathrm{i}}=\frac{40 \cdot 308,9 \cdot 10^{3}}{134138}=92,1[\mathrm{kN} / \mathrm{m}]
$$

where:

$\mathrm{K}_{\mathrm{i}}$ - stiffness of a single spring $[\mathrm{N} / \mathrm{m}]$;

$\mathrm{C}_{\mathrm{z}}=40[\mathrm{MPa} / \mathrm{m}]-$ ground stiffness coefficient, according to [7];

$A=308,9[\mathrm{~m} 2]-$ total area of legs of the structure;

$\mathrm{i}=134138[-]-$ number of springs, equal to the number of nodes on structure's legs.

Then, certain degrees of freedom were removed from the lower nodes of the springs in such a way that leg spreading could still be taken into account. In case of the leg on which the load $\mathrm{Y}$ acts (the leg does not move horizontally with respect to the seabed), the upper nodes of the springs were deprived of ability to move in the XY plane, while they were still able to move in the Z-direction. The motion of the nodes situated at the lower ends of the springs supporting the structure was blocked in all three directions. This solution provided opportunities for analysing the effect of the interaction between the seabed and the base of the structure. Some changes were also introduced to the geometry of the structure. The sheeting of the side walls of the hoops in the area of connections with the horizontal pipes was reinforced with four vertical stiffeners of $T$ type (300x30x200x30), while the pipe segments situated inside the hooks were reinforced with gussets of $30 \mathrm{~mm}$ in thickness.

The cylinder sheeting between the legs coming into it was reinforced with additional horizontal ring segments. The way of model fixing and the results of simulation calculations for the structure with the introduced changes are shown in Figs. 16 and 17.

As had been expected, the obtained results have revealed the effect of seabed plasticity on the deformations and stresses of the structure, in particular in the contacting areas of the main structure elements in which the maximal stress increment amounted to about $6 \%$. Additionally, the forces exerted by the legs of the structure on the bottom of the water region were calculated. For the foot on the direction of which the load acts the force was equal to $1,02 \mathrm{MPa}$, while for the remaining two legs it was $0,68 \mathrm{MPa}$ for each. The analysis of the obtained results proves their qualitative correctness, which provides good opportunities for further perfecting of the examined model. 


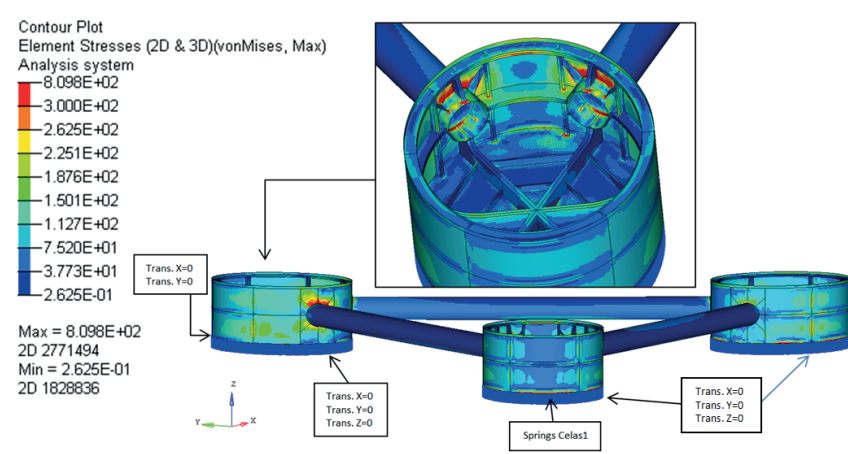

Fig. 16. Model fixing, reduced stresses [MPa]

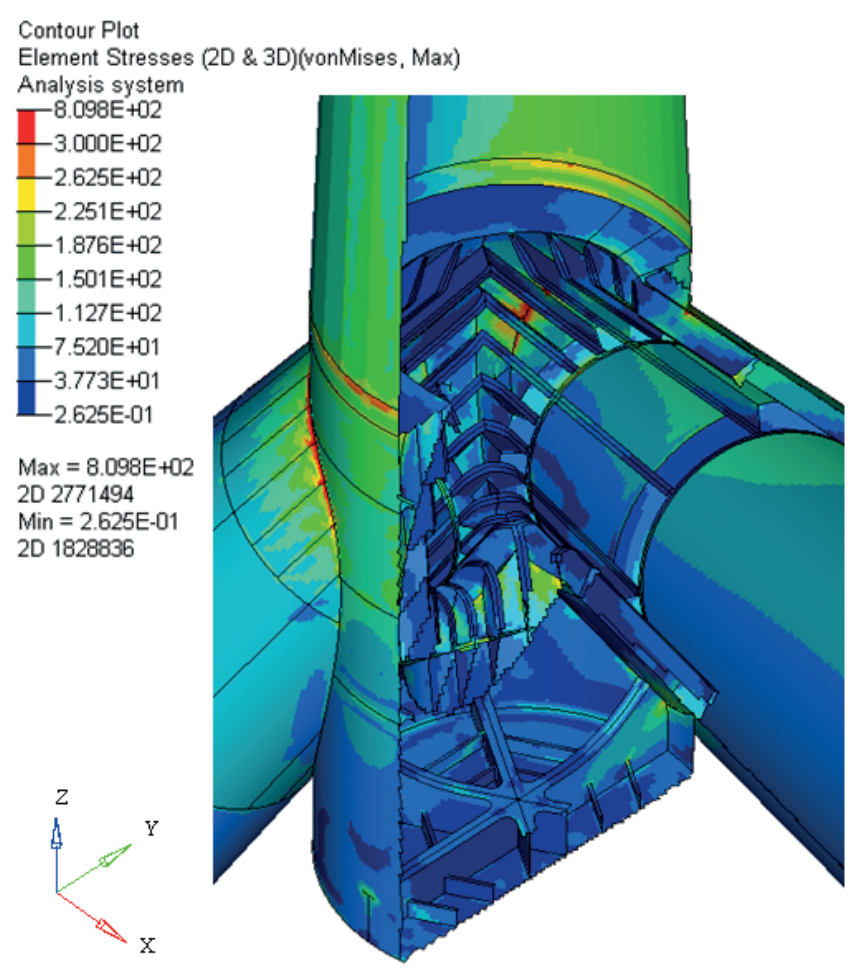

Fig. 17. „Cylinder”, reduced stresses [MPa]

\section{FINAL STAGE OF MODIFICATION. CHECKING CALCULATIONS}

The last modification has led to the structure which meets the assumed strength criteria. However, due to high stresses still existing in the leg/cylinder connection area, the thickness of the sheeting of the legs above the last upper ring was increased to $40 \mathrm{~mm}$. Also a decision was made to make the central part of the leg sheeting, in which the stress level was relatively low, using a thinner, $24 \mathrm{~mm}$ sheet, additionally reinforced with three rings $\mathrm{T} 300 \times 24 \times 200 \times 20$ to prevent possible stability loss (buckling) of the sheeting. Positions of these rings are marked in Fig. 18. Moreover, some changes were introduced in the hoop area to reduce stresses. After analysing the results taking into account the seabed elasticity, the bottom plate of the structure was reinforced with additional radially distributed bulb flats $370 \times 16$. The sheets of the side sheeting in the horizontal pipe entry areas, between the outer vertical stiffeners, were thickened to $40 \mathrm{~mm}$. The ending parts of the horizontal pipes which entered into the hoops were made of 40-mm thick sheet. Additionally, to stiffen their free edges, inner rings of $30 \mathrm{~mm}$ in thickness were mounted on the ends of these pipes. The thickness of the remaining elements remained unchanged, compared to the previous version. Figure 18 shows the structure of the legs after introducing the above changes.

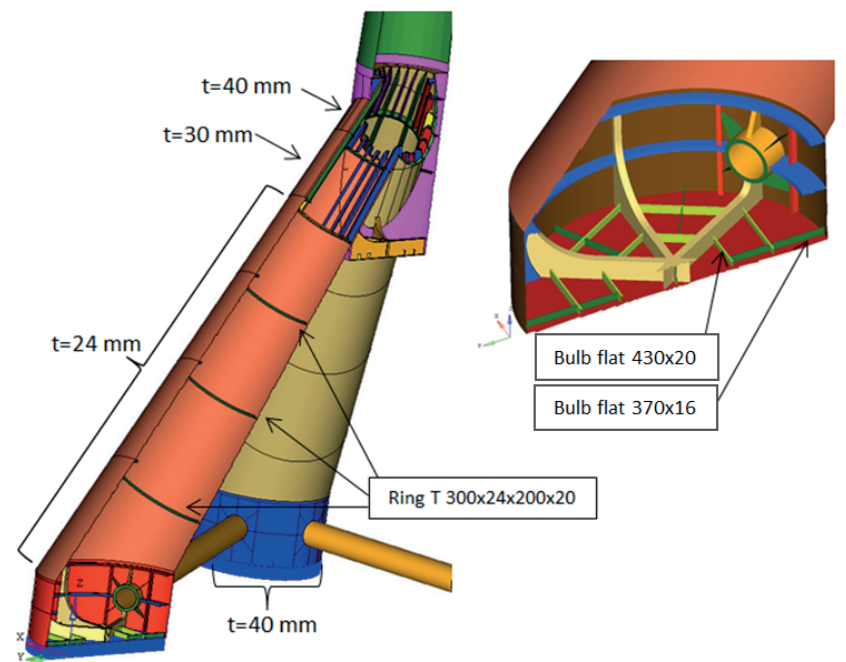

Fig. 18. Geometry of the support structure after optimisation.

Figures 19 and 20 show the stresses and deformations of the final version of the support structure. Based on their analysis we can conclude that the highest stresses, exceeding $400 \mathrm{MPa}$, only occur in single finite elements of the model, in the connection areas of structure elements. It is noteworthy that the calculations making use of $2 \mathrm{D}$ coating elements can reveal unrealistically increased stresses in the areas of rapid geometry changes, therefore the authors allowed the critical stresses to be slightly exceeded in the one-element band from the edge connecting two elements of the structure.

In order to obtain more reliable results in the contacting areas of main elements of the structure, additional zonal analyses are to be performed with the use of $3 \mathrm{D}$ elements for selected areas.

The strength of the structure in the above described areas will be ensured for the assumed load distribution by the use of high-strength steel.

The mass of the structure after the introduced changes concerning stiffeners and sheet thickness is equal to $1582 \mathrm{t}$.

\section{SELECTED ECONOMIC ASPECTS}

For the final support structure, additional parameters were calculated which can be of certain importance for investors as affecting the predicted investment costs. As already mentioned, the mass of the steel structure is equal to about $1582 \mathrm{t}$, without welds and preservation coatings. The information on the mass of the foundation and the unit cost of production of $1 \mathrm{~kg}$ of ship steel structures, which at present amounts to about $4 €$, enables to assess the cost of production of the steel structure alone as approximately equal to $6.328 .000 €$. Based on the structure geometry analysis, the volume of the inside of the 
foundation to the predicted level of ballast filling was also calculated as approximately equal to 9 thousand m3. Taking into account that the role of ballast will be played by the pulp in the form of wet gravel having the unit mass equal to 1700 $\mathrm{kg} / \mathrm{m} 3$, the mass of the entire ballast will equal $15300 \mathrm{t}$, which at the current unit price equal to about 25 PLN (6€) for $1 \mathrm{~m} 3$ of the pulp gives $91800 €$.

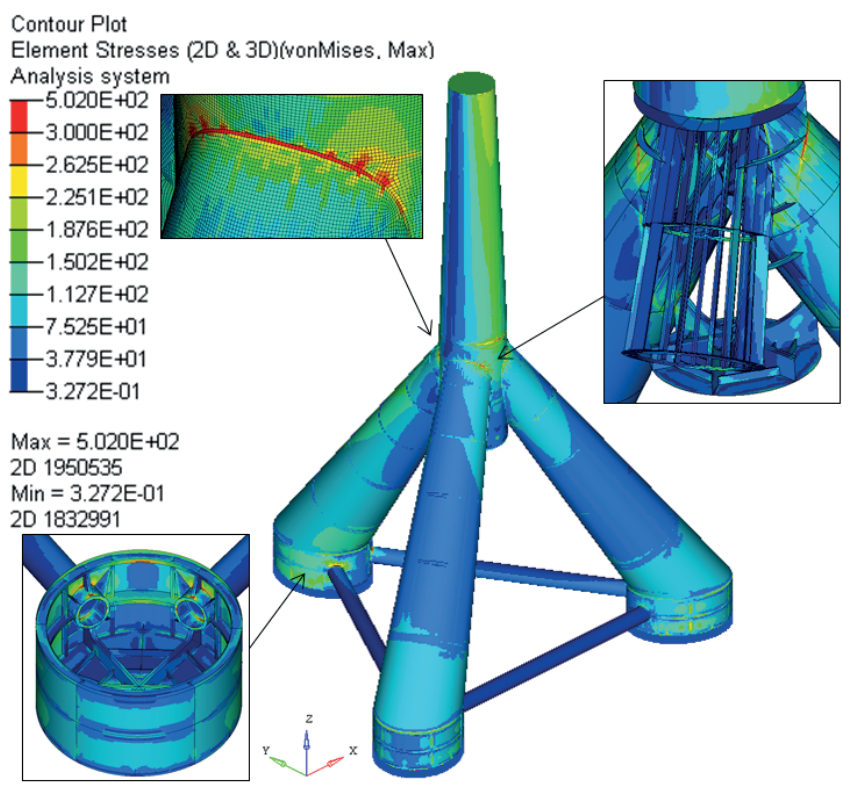

Fig.19. Reduced stresses [MPa]

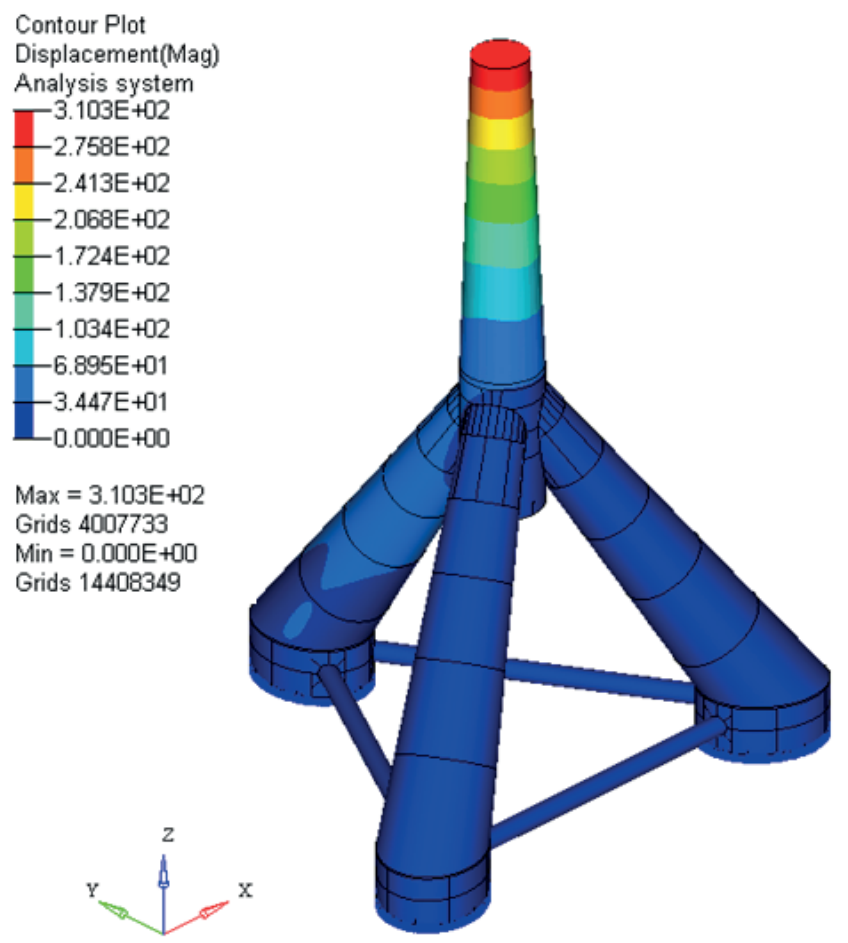

Fig. 20. Elastic deformations $[\mathrm{mm}]$

\section{SUMMARY}

The article refers to current, and simultaneously very complex and important issues connected with designing marine objects to support large wind power plants. Authors made an attempt to design a steel support structure of a tripod type which is intended to be fixed on the Baltic seabed, at a depth of about $60 \mathrm{~m}$. Structures of this type which were built in the past were installed at smaller depths and linked with the seabed using piles. The here presented structure is of gravitational type, hence a number of difficult and completely new problems were to be solved. It was done by successive modifications of the designed structure with respect to its both geometrical and strength parameters, and to work out numerical models and perform calculations with the aid of advanced numerical codes. The presented final version of the structure meets the assumed requirements. The mass of the structure is comparable with the mass of another simultaneously designed steel structure, also of gravitational type, which is intended to be founded at the depth of $40 \mathrm{~m}$.

It is noteworthy that over $85 \%$ of the total mass of the structure is planned do be made of normal strength hull structural steel (class NV B - Re 235, according to [8]). This makes this project more advantageous and attracting strong interest of representatives of wind farm investors. In most heavily loaded areas of the structure the steel NV AEH420 Re 420 was used, according to [8].

In authors' opinion, the article names and discusses a number of issues concerning the subject matters of designing of steel marine structures which will be highly applicable for designers, research workers, and investors interested in those types of objects. Moreover, it enables to evaluate the level of technological and material costs connected with the production of the examined object.

\section{ACKNOWLEDGMENT}

FEM analysis has been performed with HYPER WORKS software. Calculations were carried out at the Academic Computer Centre in Gdansk (TASK).

This research was supported by The Polish National Centre for Research and Development (NCBR) under the project PBS1/ A6/8/2012 "AQUILO"

\section{REFERENCES}

1. Sarpkaya T.: Wave forces on offshore structures, Cambridge University Press, 2010

2. Sarpkaya T.: In-line and transverse forces on smooth and rough cylinders in oscillatory flow at high Reynolds numbers, Monterey, California. Naval Postgraduate School, 1986

3. Recommended Practice DNV-RP-C205: Environmental conditions and environmental loads, Det Norske Veritas, October 2010 
4. Levis E.V.: Principles of Naval Architecture. Vol. III Motions in Waves and Controllability, SNAME, 1989

5. Dymarski P., Ciba E., Marcinkowski T.: Effective method for determining environmental loads on supporting structures for offshore wind turbines, 20th International Conference on Hydrodynamics in Ship Design and Operation HYDRONAV 2014, Wroclaw, Poland, June 2014

6. Turbine graphics, source: Repower (in Polish)

7. PN-80/B-03040 „Foundations and supporting structures for machines" (in Polish)

8. DNV-OS-J101 Design of Offshore Wind Turbine Structures

\section{CONTACT WITH THE AUTOR}

Czesław Dymarski, Paweł Dymarski, Jędrzej Żywicki

Gdańsk University of Technology Faculty of Ocean Engineering and Ship Technology 11/12 Narutowicza Str. 80-233 Gdańsk POLAND 